\title{
A FENOMENOLOGIA DAS RELIGIÕES E A RELAÇÃO DE SACRIFÍCIO ENTRE OS ADEPTOS DA TEOLOGIA DA PROSPERIDADE
}

THE PHENOMENOLOGY OF RELIGIONS AND THE RELATIONSHIP OF SACRIFICE AMONG THE ADEPTS OF PROSPERITY THEOLOGY

Saulo Duarte Lima Ribeiro ${ }^{8}$

${ }^{8}$ Historiador, Mestre em Ciências das Religiões e Doutorando em Ciência das Religiões e Teologia, todos pela UFPB. Email: saulo@cidadeviva.org 


\section{RESUMO}

A Fenomenologia das Religiões busca dar uma exposição geral das diversas particularidades versáteis da religião, tornando-se assim a complementação sistemática da história da relação do homem com o sagrado, estudando os modos como as religiões se desenvolvem e como se relacionam umas com as outras, assim como com o próprio ser que confere a elas sentido. Para os seguidores da chamada Teologia da Prosperidade, é necessário abrir mão de algo ao qual este confira valor (o sacrifício) para que Deus retribua ao fiel de forma abundante e ainda em vida. Este é apenas um aspecto das inúmeras nuances que compõem o fenômeno religioso entre os adeptos das igrejas seguidoras da Teologia da Prosperidade. O tipo de pesquisa utilizado foi pura, com abordagem qualitativa, fazendo uso da técnica de revisão bibliográfica. Concluiu-se que para esta teologia, o sacrifício necessariamente resulta em recompensa espiritual e material para o fiel, sendo então o sacrifício incentivado e a tal conquista celebrada e proclamada na comunidade de fé à qual o mesmo pertence.

PALAVRAS-CHAVE

Fenomenologia, Religião, Prosperidade, Sacrifício.

\section{ABSTRACT}

The Phenomenology of Religions seeks to give a general account of the various versatile peculiarities of religion, thus becoming the systematic complementation of the history of the relationship between man and the sacred, studying the ways in which religions develop and how they relate to one another others, as well as with the very being that gives them meaning. For the followers of the socalled Prosperity Theology, it is necessary to give up something to which it confers value (the sacrifice) so that God will repay the faithful abundantly and still in life. This is only one aspect of the innumerable nuances that make up the religious phenomenon among the followers of the churches who are the followers of Prosperity Theology. The type of research used was pure, with a qualitative approach, making use of the bibliographic review technique. It was concluded that for this theology, sacrifice necessarily results in spiritual and material reward for the faithful, 
and so the sacrifice is encouraged and the achievement celebrated and proclaimed in the community of faith to which it belongs.

\section{KEYWORDS}

Phenomenology, Religion, Prosperity, Sacrifice.

\section{INTRODUÇÃO}

As Ciências das Religiões no Brasil têm dentro de sua grade os estudos da chamada Fenomenologia das Religiões, que, a grosso modo, é para o estudo da religião o que a Linguística é para o estudo da língua. A experiência religiosa, foco de estudo da Fenomenologia das Religiões, consiste na convergência do homem com a divindade, com tal encontro sendo a base de boa parte das religiões. Tal fato não segue lógica diferente com as igrejas seguidoras da doutrina chamada Teologia da Prosperidade.

Mesmo sendo um país conhecido internacionalmente por suas riquezas naturais e por ter mais de 10 mil pessoas com mais de 10 milhões de dólares na conta ${ }^{9}$, o Brasil atualmente encontrase posicionado em $75^{\circ}$ no ranking ${ }^{10}$ de $\mathrm{IDH}$. Além disso, até o começo de 2018 o País deve assistir a um aumento dos atuais 2,5 milhões para até 3,6 milhões no número de pessoas vivendo na miséria, segundo a estimativa divulgada em fevereiro de 2017 pelo Banco Mundial ${ }^{11}$.

Por outro lado, em um país assolado pela pobreza e má distribuição de renda, vemos a proliferação contínua de igrejas protestantes que alcançam o público de baixa renda e outros, com grande penetração entre diversas camadas sociais e, consequentemente, grande potencial de atuação para a transformação social dos excluídos, principalmente as igrejas seguidoras da Teologia da Prosperidade, já que estas transitam bem entre as camadas mais pobres da sociedade.

Desde o surgimento da Teologia da Prosperidade, os seus seguidores têm agregado cada vez mais adeptos em todas as

\footnotetext{
${ }^{9}$ Disponivel em: <https://goo.g//RBVeZL>. Acesso em 21 jan de 2018.

${ }^{10}$ Dados do "Global Finance's 2016"

${ }^{11}$ Disponivel em: https://goo.gl/QhhbJR. Acesso em 21 de jan. de 2018.
} 
camadas sociais, de forma que as igrejas adeptas desse tipo de credo apresentam crescimento vertiginoso no País. A disseminação desse grupo não está na contramão do crescimento do número de evangélicos em geral no Brasil, visto que o segmento religioso evangélico foi o que mais cresceu em nossa Nação durante o período intercensitário.

Nos últimos 30 anos os grupos dessa linha cresceram duas vezes mais rápido que a população, atingindo o seu ápice a partir dos anos 1990, também com o advento do movimento Gospel capitaneado inicialmente pela igreja neopentecostal Renascer em Cristo (2007, p. 86) e permanecendo em crescimento contínuo, uma vez que, enquanto no ano de 1980 o Brasil tinha 6,6\% de evangélicos, o percentual em 1991 era de 9\%, em 2000 o número subiu para 15,4\% e em 2010 o grupo já alcançava 22,2\% do total da população brasileira (IBGE, 2010).

Nas igrejas seguidoras da Teologia da Prosperidade a experiência religiosa é individual e comunitária; em ambas o pressuposto é o mesmo: abrindo mão do que o participante considera valioso, Deus retribuirá ao fiel ainda mais, e o sacrifício individual é testemunhado no corpo comunitário, de forma que o sacrifício e a "vitória" são incentivados, celebrados e proclamados.

No artigo em questão analisaremos as principais nuances da própria Fenomenologia das Religiões, a presentando um rápido histórico desta área e de forma breve apresentaremos como geralmente se dá a experiência do fiel com o sagrado nas igrejas seguidoras da chamada Teologia da Prosperidade.

\section{A FENOMENOLOGIA DAS RELIGIÕES}

Atualmente as áreas metodológicas com maior predomínio na Fenomenologia das Religiões são basicamente duas abordagens teóricas, com uma estando mais voltada para a Teologia e seus estudos teológicos propriamente ditos, Exegese Bíblica, entre outros, enquanto que do outro lado existe uma linha mais direcionada para os métodos e abordagens das Ciências Sociais tanto da História quanto da Antropologia e da Sociologia.

Partindo deste pressuposto, vemos o teólogo sueco Geo Widengren (1976, p. 1, tradução nossa) explanar sobre o sentido da Fenomenologia das Religiões, dizendo que ela se esforça para 
"dar uma exposição global de todos os aspectos mutáveis da religião, tornando-se assim o complemento sistemático da história da religião. Esta dá a análise histórica, enquanto a fenomenologia da religião nos dá a síntese sistemática"12.

No estudo das religiões nos encontramos com a História da Religião (que trata da investigação positiva das religiões históricas) e a Filosofia da Religião (o passo final das Ciências das Religiões que revela, a partir da especulação filosófica, a essência do fenômeno religioso, que é a busca pela ideia absoluta por trás das manifestações religiosas). A Fenomenologia das Religiões consta em estudar as formas históricas das religiões e comparar umas com as outras, formando um manual a partir do qual se pode identificar os fenômenos religiosos, preocupação não tão presente em outros momentos históricos, como nos diz Velasco (1983, p. 20, tradução nossa) quando analisa o fato religioso da antiguidade greco-romana até o século XIX:

É curioso notar que, na literatura religiosa ocidental, já muito desenvolvida neste momento, não há um estudo objetivo do fenômeno religioso, mas, no máximo, uma especulação metafísica decorrente da própria literatura religiosa (...). Talvez por esta mesma razão, a era patrística e medieval do pensamento cristão não conheça o estudo positivo dos fatos religiosos. ${ }^{13}$

Diversos são os autores que trabalham o conceito de fenômeno, sendo eles as principais fontes de estudo na Fenomenologia das Religiões. Para Hegel (que chamava a "coisa em si" de absoluto), os fenômenos são uma série de situações e

\footnotetext{
${ }^{12}$ Dar una exposición global de todos los aspectos cambiantes de la religión, convirtiéndose así en el complemento sistemático de la história de la religión. Esta da el análisis histórico, mientras que la fenomenologia de la religión nos proporciona la síntesis sistemática.

${ }^{13}$ Es curioso observar que em la literatura religiosa ocidental, ya muy desarollada en esta época, no se produce un estudio objetivo del fenómeno religioso, sino, a lo más, una especulación metafísica surgida de la propia literatura religiosa (...). Tal vez por esta misma razón la época patrística y medieval del pensamiento cristiano no conoce el estudio positivo del hecho religioso.
} 
acontecimentos para revelar o absoluto até que ele se torne conhecido, como nos diz Dartigues (2005, p.10): "Segundo Hegel, o absoluto, sendo cognoscível, é por este fato mesmo qualificável como Si ou como Espírito, de modo que a fenomenologia é de imediato uma filosofia do absoluto e do Espírito". Chantepie de La Saussure $(1904$, p. 3) segue o mesmo raciocínio de Hegel, tratando o absoluto como base para fundamentar o seu ponto de vista, mas também trabalhando uma dependência e transdisciplinaridade no campo, crendo que a "ciência da religião deve suas descobertas e seu progresso aos campos da linguística, da filologia, etnografia, da psicologia dos povos, da mitologia, do folclore". O mesmo Chantepie de La Saussure serve como uma das mais importantes referências nestes estudos devido ao seu Manual de História das Religiões. A partir da $2^{a}$ edição deste manual, ele retira a nomenclatura fenomenologia da religião e se detém à metodologia comparativa entre as religiões históricas.

Após este período inicial, a área recebe o momento ao qual Filoramo e Prandi (1999) chamam de virada fenomenológica: a entrada da fenomenologia husserliana na consideração dos fenômenos religiosos. O principal expoente desta corrente será o Gerardus Van der Leeuw, que viria a ser o primeiro a fazer este aporte da fenomenologia da religião com a fenomenologia de Husserl. Ele vai se apropriar do método fenomenológico e da Psicologia gestaltica, estudando também as transformações desta fenomenologia de ação interpretativa ou hermenêutica, e não mais puramente descritiva, como apresentava Chantepie de La Saussure. Para o autor, a fenomenologia busca o fenômeno que, em suma, quer dizer três coisas: é algo, o algo se mostra e é fenômeno porque se mostra (VAN DER LEEUW, 1970, p. 642).

Van der Leeuw se torna mais conhecido pela sua obra de 1933, "Phanomenologie der Religion", uma exposição da fenomenologia compreensiva. Para Filoramo e Prandi (1999, p. 35), a obra de Van der Leeuw se apresenta como "uma fenomenologia da arte e uma teologia do sacramento ou um trabalho sobre a religião dos primitivos, ela constitui o sol em torno do qual gira a inteira produção do pensador holandês"

Podemos dizer que há uma divisão nesta área de pesquisa: existe uma fenomenologia filosófica da religião que aplica o método fenomenológico tal como Husserl concebeu na investigação principalmente do cristianismo nas suas mais 
diversas expressões. Na chamada fenomenologia pura não há a investigação das formas que a religião assume historicamente (tais como rito, dogma, magia, etc). Por outro lado, Gerardus Van der Leeuw se destaca a partir de pesquisas de campo colhendo relatos de experiências religiosas para então montar a sua abordagem. Além disso, ele também é visto por alguns mais como um teólogo do Cristianismo pelo fato de relacionar muitas questões da análise das religiões para a própria teologia cristã, como mais uma vez aponta o livro de Filoramo e Prandi (p.34):

(...) importantes categorias da FR de Van Der Leeuw derivam do cristianismo: de maneira que não causa surpresa o fato de encontrar na base do seu trabalho fenomenológico a tese segundo a qual a evolução religiosa da humanidade tenderia para a sua realização sobrenatural: a revelação cristã.

Para Leeuw, é necessário utilizar uma metodologia mais de compreensão que de descrição da experiência religiosa, e tal ocorre tendo como ponto de partida a análise das formas de apresentação do sagrado: os fenômenos. Para ele, a pesquisa fenomenológica tem como objetivo primordial chegar à essência da religião. Van der Leeuw aponta uma divisão entre o que seria o sujeito da religião e o objeto da religião, assim como a forma como eles se relacionam através da estrutura de poder. O objeto da religião é o divino (que é a fonte do poder) e o sujeito religioso, que é justamente quem busca compartilhar deste poder para si.

A fenomenologia busca o fenômeno. O que é o fenômeno? É o que se mostra. Isto comporta uma tripla afirmação: 10 Há qualquer coisa; 20 esta coisa se mostra; 30 é um fenômeno pelo fato mesmo que se mostra. Ora, o fato de se mostrar diz respeito tanto ao que se mostra, quanto àquele a quem isto se mostra. O fenômeno, por conseguinte, não é um simples objeto; ele não é nem mesmo o objeto, a realidade verdadeira, cuja essência seria somente recoberta pela aparência das coisas vistas. Isto ressalta uma certa metafísica. Por "fenômeno" não se entende mais qualquer coisa de puramente subjetivo, uma 
"vida" do sujeito, que estuda uma parte distinta da psicologia - por mais que haja a possibilidade. Mas o fenômeno é, ao mesmo tempo, um objeto que se reporta ao sujeito e um sujeito que se refere ao objeto. [...] Toda sua essência consiste em se mostrar, se mostrar a "alguém". Tão logo esse "alguém" comece a falar do que se mostra, faz-se a fenomenologia. (VAN DER LEEUW, 1948, p. 654).

Outros dois grandes referenciais muito utilizados na Fenomenologia são Mircea Eliade e Rudolf Otto. Eliade trabalha no campo da oposição sagrado versus profano e na análise das estruturas morfológicas do sagrado, suas manifestações ou hierofanias, etc. Rudolf Otto focaliza na ideia de que é necessário passar pela experiência religiosa para que se possa entender a experiência religiosa e, consequentemente, se estudar o sagrado. A isto ele chama de elemento irracional da religião. Sem viver a experiência, o pesquisador até pode ter o conhecimento da parte racional da religião, no sentido de conhecer a teologia, a dogmática e outras nuances, mas para chegar ao conhecimento nato do sagrado, é necessário entrar no elemento irracional da religião, que só pode ser alcançado de forma empírica, por meio do sentimento, da experiência. Vemos essa posição de Otto já no prefácio de O Sagrado, em que Oneide Bobsin, buscando explicar o autor do livro, nos diz (2007, p. 19):

Para outros ainda, o Sagrado se perde nos meandros da experiência religiosa, confundindo se com ela. De fato, a experiência tem relevância, pois, como em Kant, o conhecimento se dá a partir dela. No entanto, o sagrado é a priori, ou seja, não nasce da experiência religiosa. Nesse sentido, os adeptos da experiência como critério da eficácia da presença do sagrado não encontrariam sustentação de suas teses na obra de Otto. Também não faltam críticas que consideram Otto um precursor cristão da New Age, justamente por colocar em realce a experiência religiosa. 
Em relação a esta necessidade da experiência, vemos que Otto faz um paralelo com o pensamento de Kant em A Crítica da Razão Pura (2007, p. 150) e desenvolve o tema a partir de sua própria noção do numinoso, esta influência do sagrado na vida de quem se relaciona com ele por meio da experiência religiosa. Deste modo, o pesquisador não chegará à lógica do conhecimento a respeito do sagrado se não participar da experiência que este sagrado proporciona. Para ele, o numinoso é elemento fundamental para todo o que pretende chegar à compreensão do objeto (2007, p. 151):

O sentimento do numinoso é desse tipo. Ele eclode do "fundo d'alma", da mais profunda base da psique, sem dúvida alguma nem antes nem sem estimulo e provocação por condições e experiências sensoriais do mundo, e sim nas mesmas e entre elas. Só que não emana delas, mas através delas. Trata-se de estímulo e "desencadeamento" para que a sensação do numinoso se ative, ao mesmo tempo em que, inicialmente de forma inadvertida e imediata, se entrelace e entreteça com o mundano-sensorial, para então empreender gradativa purificação, afastando de si este ultimo e colocando-o como oposto a si próprio. A prova de que a sensação do numinoso consiste em elementos cognitivos estritamente apriorísticos deve ser levada a cabo mediante auto-reflexão crítica.

Se por um lado Otto diz que a experiência é justamente a experiência da irracionalidade no aspecto de alteridade do sagrado (que se mostra como o outro lado inacessível), por outro, para Husserl (1992, p. 13), a descrição fenomenológica é a descrição da experiência, que é a relação entre o sujeito e seu objeto (chamado por ele de consciência intencional). Deste modo, vemos que Otto caminha sua análise do sagrado a partir da perspectiva de um mapeamento da experiência a fim de que o que a vive possa se reconhecer ou não nela. Em suma, o que a obra de Otto deixa evidente é que, para ele, a compreensão do que se designa irracional só ocorre a partir do momento em que se vive a experiência com o sagrado, posto que o próprio sentido de irracional à maneira de Otto só existe partindo deste pressuposto: 
a imprescindível relação vital com este sagrado, ativando a sensação do numinoso.

Para a Fenomenologia clássica, o fenômeno ou fato religioso em si, pode ser colocado como o acontecimento, o objeto religioso a ser investigado. O que por vezes gera conflito é a atitude de relacionar fenômeno como sendo o mesmo que experiência. A experiência seria o modo como o fenômeno acontece para o sujeito. Um peregrino religioso quando se dirige ao seu lugar de devoção, por exemplo, está vivendo a experiência de visitar o local sagrado. Por outro lado, o pesquisador está um passo atrás disto, ele toma distância, não o fosse, ele também seria sujeito da experiência.

Desta forma, o pesquisador contempla o fenômeno com um certo distanciamento, não vivenciando a experiência, se contrapondo à afirmação de Otto de que justamente seria necessário passar pela experiência para que se pudesse relatar o que seria o sagrado. Em suma, o pesquisador convive, observa e participa, mas ainda assim tais atos não significam que o mesmo esteja na experiência religiosa, posto que sua função se resume a observar a experiência acontecer com outras pessoas para formular suas conclusões disto. A esta "contemplação ausente de emoção" Edmund Husserl (1989, p. 154) dá o nome de epoché14, que seria a suspensão do juízo mediante a coleta dos fatos investigados, de forma que, em seu percurso, o pesquisador reconhece o objeto ideal (o noema) e chega à redução à ideia ou "redução eidética".

Não obstante o grau de importância de Otto e Mircea Eliade na utilização de suas leituras para a Fenomenologia das Religiões, a rigor, eles dois não se reportam diretamente à metodologia fenomenológica. A despeito deste fato, alguns pesquisadores classificam ambos como fenomenólogos pela grande contribuição que os dois oferecem ao horizonte teórico da Disciplina.

Para alguns pesquisadores, existe um reducionismo preocupante, visto que, quando há a identificação da religião como categoria ontológica, o sagrado passa a ser considerado elemento

\footnotetext{
${ }^{14}$ Esta suspensão de juízo denominada epoché não é criação de Husserl, mas é oriunda ainda dos céticos gregos, principalmente Pirro. Para estes, tal atitude era a única capaz de levar o indivíduo ao estado de serenidade.
} 
de livre iniciativa, sem necessariamente haver a necessidade de dada relação com o homem. Desta forma, esta visão crê que o sagrado existe e aparece, independente da atuação do homem, independente de como a religião a "catalogue", como traz Eliade (2000, p. 19):

Se qualquer coisa pode incorporar a sacralidade, em que medida permanece válida a dicotomia sagrado-profano? Esta contradição é só aparente, porque, se é verdade que qualquer coisa pode tornar-se uma hierofania, e que, provavelmente, não existe nenhum objeto, ou ser, ou planta que em certo momento da história e em certo lugar do espaço não tenha assumido o prestígio da sacralidade, nem por isso deixa de continuar a ser verdade que não se conhece nenhuma religião ou raça que tenha acumulado, ao longo de sua historia, todas as suas hierofanias. Por outras palavras, ao lado dos objetos ou dos seres profanos sempre existiram, no quadro de qualquer religião, objetos ou seres sagrados (...). Temos de ir mais longe: ainda que certa classe de objetos possa receber o valor de uma hierofania, há sempre objetos, nessa classe, que não são investidos desse privilégio.

Uma outra maneira de se lidar com o sagrado é mais pragmática, quando determinados elementos são totalmente direcionados para a prática ritualística, não havendo possibilidade de seu uso de forma que seja considerada, segundo as regras de dado ritual, como profana. Nesse sentido e nessa interpretação (discordando de Otto, Eliade e outros pesquisadores que servem de base para muito do que é estudado na Fenomenologia das Religiões), seria o ser humano quem torna dado objeto sagrado, retirando de seu uso cotidiano e o separando para uso específico, reservado às divindades ou a quaisquer outras representações do que é o sagrado. Da mesma forma, é o mesmo ser humano quem retira desse objeto a característica de ser considerado sagra do assim como algo é consagrado, ele também pode ser profanado, maculado, desfazendo o processo de consagração. 
Devido a geralmente estar dentro de uma estrutura de pensamento mais teológica, a Fenomenologia das Religiões comumente é acusada de estar mais voltada especificamente às pesquisas no âmbito da Teologia mesmo, fragilizando, ainda que não invalidando totalmente, parte de sua função enquanto método investigativo. Não obstante o seu grau de influência nas Ciências das Religiões e a quantidade de pesquisadores que se dedicam a estes estudos em Fenomenologia, ainda com alguns textos sendo publicados, alguns críticos consideram que esta área perdeu muita força no Brasil, com uma sensível diminuição no número de livros, artigos e debates que trabalhem especificamente tendo como objetivo esta temática.

Um pequeno exemplo desta perda de força estaria evidente em uma coincidência ocorrida justamente com o livro considerado um dos mais importantes na Fenomenologia das Religiões: O Sagrado, de Rudolf Otto. Não obstante tal grau de importância, no próprio Prefácio do livro, quando Walter O. Schlupp (tradutor da edição para o português) escreve a respeito da relevância da obra, ele traz a seguinte constatação (2007, p. 9): “Ninguém precisa ser profeta para prever que, no ano de 2017, também no Brasil haverá congressos e publicações das mais diversas faculdades em homenagem aos cem anos de influência de O Sagrado e seu autor." Infelizmente, contrariando a profecia, praticamente não houve sequer um grande congresso especificamente sobre a temática em 2017 no Brasil. A abordagem teórica da fenomenologia ultimamente tem se restringido mais notadamente aos estudos de filosofia.

Para contrapor tal afirmação dos críticos, alguns fenomenólogos como Carlo Greco (2009, p. 43), citam que Mircea Eliade continua sendo muito usado, como de fato isso pode ser percebido. Por outro lado, os que se contrapõem a esta defesa respondem que, ainda que seja muito utilizado, Eliade pode ser tomado fora do campo da Fenomenologia, posto estar ele mais no âmbito do historiador das religiões que do fenomenólogo. Para estes críticos da Fenomenologia das Religiões, esta área se limitaria mais ao estudo das religiões que lidam com o conceito de sagrado, como o Cristianismo. Segundo esta ideia, tal área não conseguiria descrever, por exemplo, as experiências do Budismo. As descrições do sagrado em Otto, por exemplo, podem substituir o sagrado por divino, o sagrado por "experiência de Deus", o que não se encaixaria no ateísmo do Budismo, por exemplo. Daqui poderão 
se desenvolver uma série de problemas teológicos e epistemológicos.

\section{A LÓGICA SACRIFICIAL NA TEOLOGIA DA PROSPERIDADE}

A Teologia da Prosperidade tem como ponto de partida para sua propagação no Brasil o início da década de 70, com o advento de alguns grupos, sendo o mais conhecido a Igreja Universal do Reino de Deus.

Apesar da Teologia da Prosperidade ser uma doutrina independente de dado grupo eclesiástico, é devido a estas igrejas que esta crença tem se espalhado no Brasil de forma tão rápida nos últimos anos.

Desde a Idade Média a Igreja Cristã costuma se envolver no discurso e na prática da relação de troca com o sagrado. Naqueles tempos, o Catolicismo prometia a vida eterna em troca de valores cujo propósito terreno principal seria a construção da atual Basílica de São Pedro. Nas chamadas indulgências os fiéis colocavam sua confiança a fim de que pudessem ter suas almas libertas do fogo do inferno na eternidade.

Para os seguidores da Teologia da Prosperidade, a lógica da relação do fiel com o sagrado segue necessariamente o caminho do sacrifício, mas não mais primordialmente focado na vida eterna, pelo contrário, aponta para os benefícios da própria vida terrena: o devoto sacrifica algo, entregando isto a Deus a fim de receber uma outra coisa em troca, agora a conquista de bens materiais.

Nesta relação, o devoto que se aproxima com o alvo de seu culto é empoderado na medida em que se esvazia (geralmente de seu carro, seus bens, do que tiver valor e for considerado material e passageiro) e faz o seu sacrifício, processo que Gerardus Van Der Leeuw apresenta de forma mais detalhada em suas obras tratando como "compartilhamento do poder divino".

No afã de ter os seus espaços de culto bem servidos de público, os líderes destas igrejas comunicam nas TV's, rádios e meios afins os testemunhos de curas físicas, espirituais, emocionais e, principalmente, das finanças, como resultados bemsucedidos dos "desafios" dos fiéis com Deus, propagando a 
esperança de uma vida melhor no coração dos que atualmente sofrem.

Como forma de testificar o que é "vendido" (a cura, a prosperidade financeira, a restauração de problemas diversos), é necessário ter algo maior, mais poderoso que referende a promessa. No caso do Protestantismo (seio das igrejas Neopentecostais), a própria Bíblia Sagrada - livro que é regra geral de fé e prática - seria o melhor propagandista, visto que, segundo as interpretações deste grupo (quase sempre desrespeitando as regras da Exegese bíblia nestes contextos), ela corrobora os ensinos.

Isso é visto no discurso proferido durante os cultos e nos materiais seguidos pelos adeptos. A fim de trazer credibilidade aos ensinos, os pregadores costumam utilizar testemunhos de "vitórias" dos fiéis nas diversas áreas de suas vidas a fim de que isto instigue os ouvintes a que também participem dos rituais de sacrifício financeiro, de modo que, com o discurso impregnado em todo o escopo da igreja, qualquer capítulo ou versículo bíblico recebe a interpretação que os líderes pretendem passar, gerando obediência dos fiéis na certeza de que o próprio Deus conduz aquela liderança neste processo de entregar algo a Deus e receber muitas vezes mais a abundância financeira, a prosperidade material.

Um exemplo de tal ação de imputar à Bíblia a prova de que tais doutrinas são coerentes (quanto ao uso dos dízimos e ofertas como sacrifício que gera benefícios ao doador) está na hermenêutica empregada no texto considerado o mais utilizado pelos seguidores desta Teologia, retirado de um dos trechos do Livro de Malaquias (MI. 3:10-11), que diz:

Trazei todos os dízimos à casa do tesouro, para que haja mantimento na minha casa, e depois fazei prova de mim nisto, diz o Senhor dos Exércitos, se eu não vos abrir as janelas do céu, e não derramar sobre vós uma bênção tal até que não haja lugar suficiente para a recolherdes. E por causa de vós repreenderei o devorador, e ele não destruirá os frutos da vossa terra; e a vossa vide no campo não será estéril, diz o Senhor dos Exércitos. 
Para boa parte dos teólogos o texto é interpretado de forma equivocada, posto que, na lei do culto no Antigo Testamento, havia a determinação de que o israelita deveria trazer para o templo dez por cento do que ele tinha, quer fosse dez por cento do rebanho, do alimento, etc. Tal contribuição era administrada de forma que o povo que também servia a este Deus no ofício de levitas fosse auxiliado e o templo tivesse condições de se sustentar. Como muitos não estavam fazendo isso, então um mensageiro (chamado aqui de Malaquias, que pode não ser um nome próprio, mas literalmente o significado do nome em hebraico, que é "mensageiro") escreve por volta de 340 a.C. sobre isto. Em uma região muito assolada por gafanhotos e passando por período de seca, o mensageiro diz que Deus está prometendo que, caso voltem a sustentar o templo, ele abrirá as janelas dos céus (trará chuva) e espantará o devorador (literalmente gafanhotos) - ou seja: contexto bem diferente do vivido atualmente. Em relação a esta troca de favores, o teólogo Augustus Nicodemus diz (2012, p. 122-123) diz:

Gostaria de examinar essa questão de maneira dissociada da ideia defendida pela pregação da teologia da prosperidade, pois essa teologia faz uma leitura fora do contexto. As pessoas fazem uma relação imediata entre uma coisa e outra. Elas perguntam: "Você quer ser próspero? Quer ser abençoado financeiramente? Dê o dízimo". Mas não é isso que o texto em evidência ensina. A questão que o texto destaca é a desobediência a Deus. (...) O que Deus abençoa não é o dízimo em si que você consagra a ele. O que ele abençoa éa obediência, o coração reto, o desejo de agradar a Deus. (...) esse ensino dos televangelistas adeptos da teologia da prosperidade faz uma leitura errada de Malaquias e da Palavra de Deus como um todo (...).

Neste sentido, compreendendo o texto de forma deturpada, o principal motivo que levaria os fiéis das Igrejas Neopentecostais a entregarem valores no culto seria justamente a troca sacrificial: a pessoa devolve o dízimo ordenado no Antigo 
Testamento e dá suas contribuições para ser abençoada financeiramente.

Tal fenômeno consequentemente promove grande crescimento no número de membros, posto que muitos - quer carentes financeiramente ou não - desejam prosperar materialmente. Consequentemente, tal crescimento no número de membros reverbera também no crescimento no número de templos deste perfil em regiões diversas do Brasil (SILVA, 2004).

Para a corrente doutrinária em questão, qualquer tipo de sofrimento advém da falta de fé ou de práticas de pecado pelo devoto, de forma que é necessário desenvolver fé, mas não apenas dizer ou acreditar nisso, mas apresentar esta fé por meio de atos sacrificiais, de maneira que, havendo o ato sacrificial e a fé, necessariamente incorrerão prosperidade material e saúde física, espiritual e emocional, chamados pelos seguidores da doutrina de marcas do cristão cheio de fé. $O$ discurso dos seguidores desta doutrina está pautado em uma espécie de troca de favores do homem com Deus. Sobre esta questão, o líder da Igreja Universal do Reino de Deus (que atualmente é a mais conhecida igreja que segue esta linha no Brasil), Bispo Edir Macedo (1996, p.12) diz:

Dependendo do grau de interesse do ofertante, o presente, por mais caro que seja, ainda assim se torna barato diante daquilo que está proporcionando ao presenteado. Quando há um profundo laço de afeto, ternura e amor entre o que presenteia e o que recebe, o presente nunca deve ser inferior ao melhor que a pessoa tem condições de dar.

Em relação às contribuições financeiras dos fiéis que seguem esta doutrina, Mariano (1999, p. 44) diz: "o principal sacrifício que Deus exige de seus servos é ser fiel nos dízimos e dar generosas ofertas com alegria, amor e desprendimento". O discurso dos líderes que apregoam esta doutrina é de que o fiel 
deve investir seu dinheiro ou bens materiais com a convicção, a fé de que receberá o retorno desejado, pois Deus vai pagar de volta o investimento. Não apenas isso. Em suas pregações, os proclamadores da Teologia da Prosperidade direcionam o público para a relação sacrificial entendendo que o próprio Jesus usava roupa de grife, morava em casa de luxo e tinha um ministério com muito sucesso financeiro ${ }^{15}$. Desta forma, não é possível que o Deus que enviou seu filho para viver desta forma também não queira contexto semelhante para os seus atuais seguidores, como nos diz o pastor americano Kenneth Hagin, um dos maiores nomes do movimento da Teologia da Prosperidade (1985, p.55): “Deus quer que seus filhos usem a melhor roupa. Ele quer que eles dirijam os melhores carros e quer que eles tenham o melhor de tudo... simplesmente exija o que você precisa!"

A fim de receber as bênçãos que espera de Deus, é necessário que o devoto firme seu compromisso, seu voto com Deus, de forma que, enquanto que da terra brota o sacrifício do bem material, do dízimo e da oferta, do céu desce a bênção de Deus em forma material, em forma de bênção financeira, sinal do cumprimento da promessa de Deus para o seu povo fiel dentro desta visão teológica, o dízimo é, antes de tudo, um "contrato: ao ofertar à casa do senhor, o crente coloca-se na condição de credor, praticamente obrigando a Deus a retribuir-Ihe com riquezas na medida de sua contribuição". (PROENÇA, 2002, p.113).

\section{CONSIDERAÇÕES FINAIS}

Para a Fenomenologia clássica, o fenômeno ou fato religioso em si, é colocado como o acontecimento, o objeto religioso a ser investigado. No caso da Teologia da Prosperidade, a investigação paira sobre diversas nuances, e a principal poderia ser apontada como a forma em que a relação do homem com o sagrado se dá a partir de uma troca: o devoto tem interesse pelas bênçãos de Deus, enquanto este outro promete derramar

\footnotetext{
${ }^{15}$ A fim de corroborar tais teses, não é difícil encontrar líderes que dizem que a Bíblia relata que o manto de jesus era de uma costura só, e tal informação quer dizer que era um padrão de vestuário que um pobre não poderia usar. Além disso, Jesus andava de jumento, que seria o carro de luxo da época. Outra passagem bastante utilizada é a de Judas ser tesoureiro do grupo. Quase sempre tal afirmação vem seguida da conclusiva: "só um ministério próspero financeiramente necessitaria de um tesoureiro.
} 
prosperidade financeira sobre o praticante, conquanto receba do próprio Deus valores materiais.

Segundo esta lógica, alguns líderes de tais instituições lucram com os valores investidos pelos praticantes, enquanto tal prática se espalha de maneira vertiginosa pelo país, com objetivo maior de atrair novos seguidores não tão preocupados com o compromisso teológico, mas com a filiação em torno mais de um projeto expansionista para proclamação de sucesso material do que em um propósito por deixar erros de lado para demonstração de mudança de caráter e atuação pela transformação dos ambientes que os cercam.

\section{REFERÊNCIAS}

BÍBLIA, Português. A Bíblia Sagrada: Antigo e Novo Testamento. Tradução de João Ferreira de Almeida. Edição Corrigida Fiel. São Paulo: ICP, 2000.

CAILLOIS, Roger. El Hombre y lo Sagrado. México: FCE, 1996.

CALEIRO, João Pedro. Quantos são e quanto ganham as pessoas mais ricas do Brasil. Economia. Revista Exame, Editora Abril, 30 Out. 2015. Disponível em: $<$ http://exame.abril.com.br/economia/quantos-sao-e-quantoganham-as-pessoas-mais-ricas-do-brasil/> Acesso em 21 de janeiro de 2018.

CUNHA, Magali do Nascimento. A explosão gospel: um olhar das ciências humanas sobre o cenário evangélico no Brasil. Rio de Janeiro: Mauad X, Mysterium, 2007.

DARTIGUES, André. 0 que é a Fenomenologia? São Paulo: Centauro, 2005.

ELIADE, Mircea. Tratado de História das Religiões. São Paulo: Martins Fontes. 2000.

FILORAMO, G.; PRANDI, C. As Ciências da Religião. São Paulo: Paulus, 1999.

GRECO, Carlo. A Essência da Religião. In: A experiência religiosa. Essência, Valor, Verdade. São Paulo: Edições Loyola, 2009. p. 35-121. 
GLOBO FINANCE. Best banks and financial ranking. Disponível em: <https://www.gfmag.com/awards-rankings/best-banks-andfinancial-rankings/?year=2016\&search location=\&award type $>$ Acesso em 21 jan. de 2018.

HAGIN, Kenneth. Novos Limiares da Fé. São Paulo: Graça Editorial, 1985.

HUSSERL, E. General Introduction to pure Phenomenology. New York: Collins Books, [1972 (1913)]

. Conferências de Paris. Lisboa: Edições 70, 1992.

La crise des sciences européennes et la phénoménologie transcendentale. Trad. G. Granel. Paris: TELGallimard, 1989.

LOPES, Augustus Nicodemus. O culto segundo Deus. São Paulo: Vida Nova, 2012.

MACEDO, Edir. O Perfeito Sacrifício: o significado espiritual do dízimo e ofertas. Rio de Janeiro: Editora Gráfica Universal, 1996.

Vida com Abundância. 13. ed. Rio de Janeiro: Universal, 1992.

MARIANO, Ricardo. Expansão pentecostal no Brasil: o caso da Igreja Universal. In: Estudos Avançados, dez. 2004, vol.18, no.52, p.121-138.

MARTIN VELASCO, J. Introducción a la Fenomenologia de la Religión. Madrid: Cristandad. 1983.

NAÇÕES UNIDAS NO BRASIL. Número de pobres no Brasil terá aumento de no mínimo 25 milhões em 2017, aponta Banco Mundial. $2017 . \quad$ Disponível em: $<$ https://nacoesunidas.org/numero-de-pobres-no-brasil-teraaumento-de-no-minimo-25-milhoes-em-2017-aponta-bancomundial/> Acesso em 21 jan. de 2018.

OTTO, Rudolf. O sagrado: os aspectos irracionais na noção do divino e sua relação com o racional. Tradução: Walter $O$. Schlupp. São Leopoldo: Sinodal/EST; Petrópolis: Vozes, 2007.

PROENÇA, Wander de Lara. Magia, prosperidade e messianismo: o "sagrado selvagem" nas representações e práticas de leitura 
do neopentecostalismo brasileiro. Curitiba: Aos Quatro Ventos, 2003.

SAUSSAYE, P. D. Chantepie de La. Manuel d' Histoire des Religions. Paris: Libraire Armand Colin, 1904

SILVA, Dionísio Oliveira. O comércio do sagrado. Londrina: Descoberta, 2004.

VAN DER LEEUW, Geradus. La Religion dans son Essence et ses Manifestations. Phénoménologie de la Religion, Paris: Payot, 1948.

VAN DER LEEUW, Gerardus. Fenomenologia de la Religión. México: FCE. 1970.

WINDENGREN, Geo. Fenomenologia de la Religión. Madrid: Ediciones Cristandad, 1976. 